\title{
Editorial: Conflict Resolution
}

In the 1990s 'conflict resolution' was a good phrase. With the ending of what had then seemed the conflict, the really big conflict, all the little conflicts could be resolved by the techniques of conflict resolution. (Never mind that in the last days of the Soviet empire far more people were being killed in little conflicts than by the big one.) All that was to be needed for the "new world order was a modicum of goodwill, some international peace-keepers and negotiators trained in 'conflict resolution'. The fact that it would have been hard to point to a single conflict which had actually been solved by the methods of conflict resolution (and certainly the big one had not been) was taken to be carping and beside the point.

Conflicts are sometimes resolved, sometimes by force, sometimes by old believers dying out, sometimes by the parties getting richer and less interested in conflict, sometimes just by the parties getting tired or even forgetting whatever it was they had actually been fighting about, and sometimes by the onset of a grudging respect for enemies one never really hated and with whom one finds one can, after all, live. Sometimes they just stop for no ostensible reason at all.

But that there is a technique for conflict resolution looks like a rationalist mirage, a characteristic piece of the third-wayism of which it was a small but significant element. For what underlies such a belief is the premise that parties to a conflict typically share enough beliefs and principles to enable them to lay down their arms and agree among themselves by the application of appeals to reason and mutual self-interest. This surely is to misunderstand the nature of conflict, for most of the cases of conflict in the modern world which readily come to mind are cases where the protagonists have fundamental disagreements of principle or claim, and where violence has been resorted to precisely because there are feelings of great strength on both sides and no common ground of principle. Being lectured to by professional conciliators is hardly likely to do the trick. particularly where the conciliators are from a background which finds it hard to conceive of real differences of principle among reasonable people.

Well, maybe the protagonists in life and death conflict or in a battle between rival faiths are not, in that sense, reasonable. But it is patronising and, in the end, dangerous to have so attenuated a sense reasonableness that one is unable to envisage people willing to dieand kill-for their beliefs, without thereby being insane.

doi:10.1017/S003181910300041X

@2003 The Royal Institute of Philosophy

Philosophy 782003 